Research Article

\title{
Ultrasound-Accelerated, Concise, and Highly Efficient Synthesis of 2-Oxazoline Derivatives Using Heterogenous Calcium Ferrite Nanoparticles and Their DFT Studies
}

\author{
Anjaneyulu Bendi $\mathbb{D}^{1},{ }^{1}$ Shalu Atri, ${ }^{1}$ G. B. Dharma Rao $\mathbb{D},{ }^{2}$ Mohd Jamshaiya Raza, ${ }^{1}$ \\ and Nutan Sharma ${ }^{1}$ \\ ${ }^{1}$ Department of Chemistry, Faculty of Science, Shree Guru Gobind Singh Tricentenary University, Gurugram-122505, \\ Haryana, India \\ ${ }^{2}$ Department of Chemistry, Kommuri Pratap Reddy Institute of Technology, Hyderabad 500088, TS, India
}

Correspondence should be addressed to Nutan Sharma; nutan28@gmail.com

Received 9 August 2021; Revised 24 September 2021; Accepted 27 September 2021; Published 21 October 2021

Academic Editor: Gang Feng

Copyright ( $) 2021$ Anjaneyulu Bendi et al. This is an open access article distributed under the Creative Commons Attribution License, which permits unrestricted use, distribution, and reproduction in any medium, provided the original work is properly cited.

\begin{abstract}
A rapid and operationally simple approach for synthesising biologically relevant 2-oxazoline derivatives has been developed through highly efficient ultrasound-promoted coupling reactions of thioamides and amino alcohols using calcium ferrite nanoparticles as heterogeneous catalysts. The major advantage of using ultrasound irradiation lies in the drastic reduction of reaction time as compared with conventional stirring. Furthermore, quantum chemical investigations for the synthesised 2oxazoline derivatives have been carried out at the DFT/B3LYP/6-311 $+\mathrm{G}(\mathrm{d}, \mathrm{p})$ level of theory to predict the optimized geometry. The molecular properties such as bond lengths, bond orders, Milliken charges, frontier molecular orbitals, global reactivity descriptors, molecular electrostatic potential map, and thermodynamic parameters of all the compounds have also been reported at the same level of theory.
\end{abstract}

\section{Introduction}

2-Oxazoline is an attractive five-membered heterocyclic scaffold which is present in many bioactive natural products [1] and pharmaceuticals [2-5]. This nucleus is part of many drug-like compounds exhibiting antifungal, neuroprotective, cytotoxic, and antibiotic activities [6]. In addition, synthetic applications of 2-oxazolines include their use as unsurpassed catalytic ligands in asymmetric syntheses [7-10], protecting groups for carboxylic acids [11], monomers for thermoresponsive polymers [12], and linear polyethylene imines [13]. Due to the immense applications, these pharmaceutically important scaffolds attract the interest of synthetic organic chemists and tremendous research efforts from the past years are focused on the development of efficient routes for the preparation of 2oxazoline derivatives. In this direction, multiple synthetic strategies which involve different substrates like imidate hydrochlorides [14], orthoesters [15], aldehydes [16-19], carboxylic acids [20-24], or their derivatives like ester [25-28], nitriles [29-33], and thioamides [34] have been developed to prepare the oxazolines. Despite the potential applications of these reported procedures, they suffer from several limitations, such as hazardous reaction conditions, expensive catalysts, longer reaction times, tedious work-up procedures, and a deficit of general applicability. Thus, the development of mild and efficient strategies is undeniably needed.

In the past few decades, ultrasound has emerged as a potent tool for a variety of organic reactions $[35,36]$. Ultrasound-promoted reactions result in shorter reaction time, reduced undesired reactions, pure products with high yields using simple open systems, and milder reaction conditions as compared to conventional heating methods. These 
advantages rightly put this technique under green, clean, and ecofriendly methodology. However, this technology has not been much exploited in the synthesis of heterocyclic ring systems [37-39]. Considering this lacuna as an opportunity and our interest in ultrasound-promoted heterocyclic synthesis [40, 41], we have developed an efficient and rapid methodology for the synthesis of 2-oxazolines.

On the other hand, magnetic nanoparticles have attracted significant attention as heterogeneous catalysts in the last few years as they enhance reusability and prevent catalytic loss because of their simple separation technique which is an attractive alternative to filtration. Catalysts that are of low cost and are readily available greatly enhance the economic viability of the chemical process. Magnetically recoverable and recyclable nanocatalysts are being used for various reduction, oxidation, and condensation reactions, and their greener generation methods and ecofriendly applications are an ideal merge for the development of sustainable pathways in organic synthesis [42-45].

Nowadays, calcium ferrite $\left(\mathrm{CaFe}_{2} \mathrm{O}_{4}\right)$ nanoparticles have attracted significant attention among other metal ferrite nanoparticles. They have significant properties like easy workup, multicycle, and cleaner reaction profiles, besides minimization of organic waste generation in comparison to conventional catalytic systems. Moreover, to the best of our knowledge, $\mathrm{CaFe}_{2} \mathrm{O}_{4}$ nanoparticles have not been exploited till now in the synthesis of 2-oxazolines. Keeping this in mind, herein we have developed a mild and efficient ultrasound-assisted methodology for the synthesis of 2-oxazoline derivatives using $\mathrm{CaFe}_{2} \mathrm{O}_{4}$ nanoparticles as a heterogeneous catalyst (Scheme 1).

Moreover, the theoretical quantum chemical calculations for all the synthesised 2-oxazoline derivatives were performed with the density functional theory (DFT) using Gaussian 09 and Gauss View 06 software. The optimized molecular geometry of the series of compounds has been computed using the DFT (B3LYP) method with a 6-311+G(d, p) basis set. In general, the DFT/B3LYP method is used to study the geometrical, spectral, and different molecular properties of chemical compounds because this method offers an excellent tradeoff between chemical accuracy and computational cost [46-49].

\section{Results and Discussion}

$\mathrm{CaFe}_{2} \mathrm{O}_{4}$ nanoparticles were synthesised by a simple coprecipitation method using $\mathrm{NaOH}$ as a precipitating agent. The synthesised $\mathrm{CaFe}_{2} \mathrm{O}_{4}$ nanoparticles were characterized by X-ray diffraction (XRD) (JNU, New Delhi), transmission electron microscopy (TEM) (IARI, New Delhi), Fourier-transform infrared (FT-IR) spectroscopy, and $\mathrm{N}_{2}$ adsorption-desorption isotherm analysis (BET analysis) (University of Delhi, New Delhi). Figure 1 presents the powder X-ray diffraction pattern of an asprepared sample, which crystallizes in orthorhombic symmetry with space group Pnma having lattice parameters $a=9.231$ (5); $b=3.005$ (2); $c=10.690$ (6) $\AA$; and $\alpha=90, \beta=90$, and $\gamma=90^{\circ}$. Crystallite size of the $\mathrm{CaFe}_{2} \mathrm{O}_{4}$ sample was calculated using Debye-Scherrer analysis and

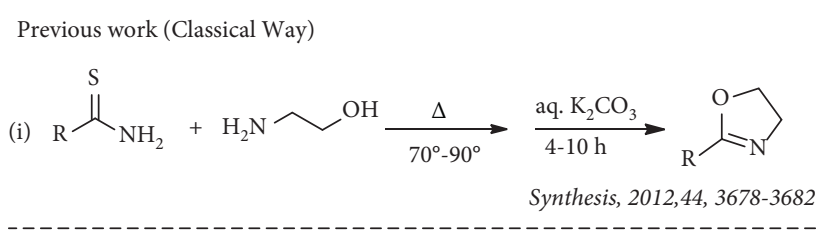

This work (Ultrasound Way)

(ii)

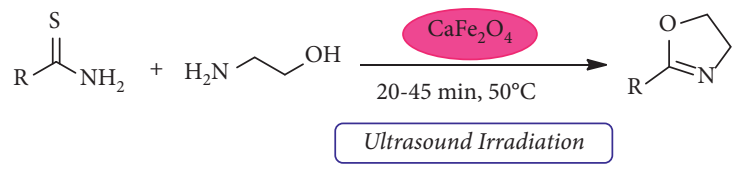

Scheme 1: Previous synthetic approach and our designed approach.

found to be $41.54 \mathrm{~nm}$. Thereby, smaller crystallite size (lies in nanoregime) is mainly accountable for broadening of the diffracted peaks. Consequently, a smaller crystallite size provides a high surface area. And by taking advantage of this, we have used $\mathrm{CaFe}_{2} \mathrm{O}_{4}$ nanoparticles as the catalyst in the synthesis of 2-Oxazoline derivatives.

TEM analysis was used to analyse the morphology of synthesised $\mathrm{CaFe}_{2} \mathrm{O}_{4}$ nanoparticles. A fully agglomerated spherical morphology was observed for the $\mathrm{CaFe}_{2} \mathrm{O}_{4}$ sample under TEM images, and crystallite size was found to be $\sim 13 \mathrm{~nm}$. Generally, agglomeration might occur due to involving low-temperature synthetic conditions and the absence of a capping agent during the synthesis of nanoparticles (Figure 2).

$\mathrm{BET}$ analysis was used to determine the surface area of $\mathrm{CaFe}_{2} \mathrm{O}_{4}$ nanoparticles. BET analysis indicates the surface area of $\mathrm{CaFe}_{2} \mathrm{O}_{4}$ nanoparticles observed to be $18.065 \mathrm{~m}^{2} / \mathrm{g}$ [50]. This increase in the surface area might be due to the smaller crystallite size of $\mathrm{CaFe}_{2} \mathrm{O}_{4}$ nanoparticles (Figure 3).

To explore the viability of the designed synthetic strategy, a model reaction was performed by using thioamide $1 \mathbf{d}$ and amino alcohol 2 at $50^{\circ} \mathrm{C}$, varying the amounts of $\mathrm{CaFe}_{2} \mathrm{O}_{4}$ nanoparticles using the ultrasound irradiation approach (Table 1). From Table 1, it is clear that using $10 \mathrm{~mol} \%$ of $\mathrm{CaFe}_{2} \mathrm{O}_{4}$ resulted in the formation of product 3d at a maximum yield of $89 \%$ (Table 1, entry 5). It should be noted here that $\mathbf{3 f}$ was obtained with a very less yield of $65 \%$ when the reaction was performed without a catalyst. This may be anticipated due to the larger surface area provided by $\mathrm{CaFe}_{2} \mathrm{O}_{4}$ nanoparticles in organic transformations. However, an increase in the amount of catalyst from $10 \mathrm{~mol} \%$ to $20 \mathrm{~mol} \%$ did not increase the yield of compound 3d.

With the optimized conditions in hand (Table 1, entry 5), we next turned our attention to the scope and robustness of the reaction by testing various thioamides $\mathbf{1 a}-\mathbf{j}$ with amino alcohol 2, and the results are summarized in Table 2. 2Oxazolines containing cyclohexyl, aryl, and heteroaryl ring as well as alkyl chain substituents were effectively synthesised in good yields.

Thiobenzamides tolerated different functional groups such as methoxy, hydroxy, and halogen under the applied reaction conditions (Table 2, entries 2, 3, and 4). Synthesis of 


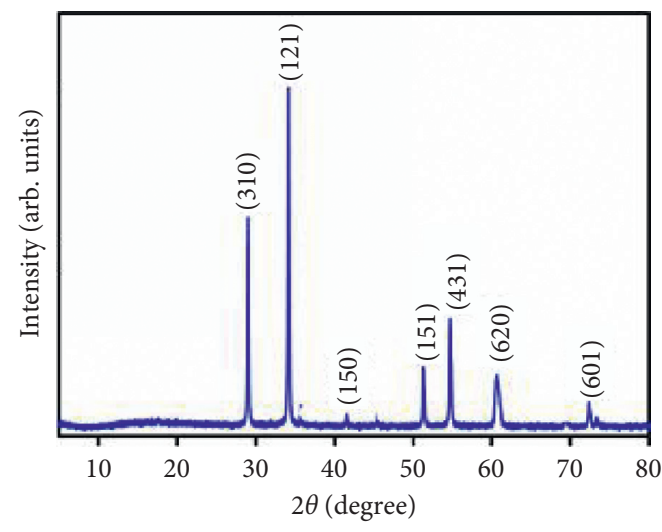

(a)

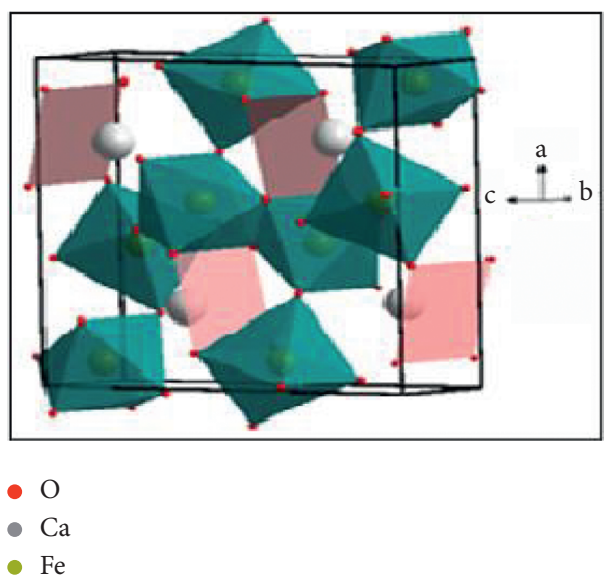

(b)

Figure 1: (a) Powder XRD pattern of as $\mathrm{CaFe}_{2} \mathrm{O}_{4}$. (b) $\mathrm{CaFe}_{2} \mathrm{O}_{4}$ crystallizes in orthorhombic symmetry.

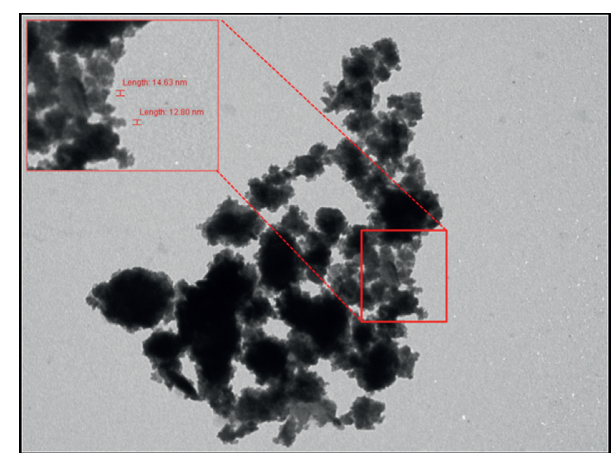

FIgUre 2: TEM image of $\mathrm{CaFe}_{2} \mathrm{O}_{4}$ nanoparticles.

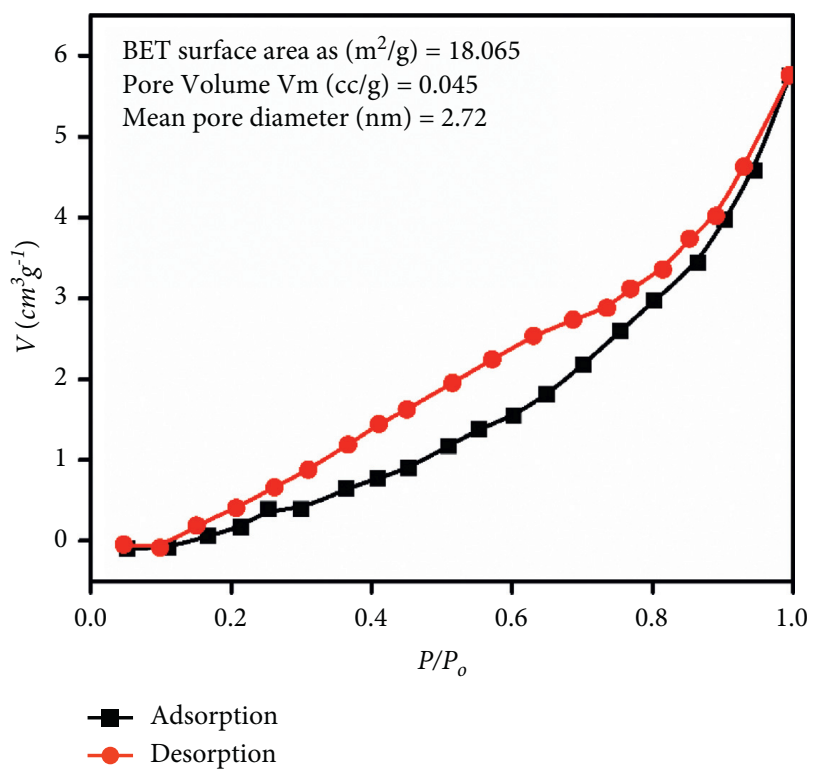

FIgURE 3: $\mathrm{N}_{2}$ adsorption-desorption isotherm.

2-oxazolines was also well accomplished by using heterocyclic thioamides (Table 2, entries 6 and 7). Analytical data of all the synthesised compounds were compared with those reported in the literature [34].
In order to justify sustainable chemistry concerns, reusability and recovery of $\mathrm{CaFe}_{2} \mathrm{O}_{4}$ were studied using the reaction of $\mathbf{1 b}$ and $\mathbf{2}$ in the presence of $\mathrm{CaFe}_{2} \mathrm{O}_{4}(10 \mathrm{~mol} \%)$ at $50^{\circ} \mathrm{C}$ for $20 \mathrm{~min}$ under ultrasonic irradiation (Table 3 ).

$\mathrm{CaFe}_{2} \mathrm{O}_{4}$ was used successfully in consecutive runs (the yield decreased from $85 \%$ to $82 \%$ after 3 runs, Table 3 ), although a weight loss of approximately $5 \%$ of $\mathrm{CaFe}_{2} \mathrm{O}_{4}$ was observed from cycle to cycle due to mechanical loss. The recycled $\mathrm{CaFe}_{2} \mathrm{O}_{4}$ nanoparticles have been characterized by $\mathrm{XRD}$; the absence of extra reflections in the PXRD pattern confirms the stability of $\mathrm{CaFe}_{2} \mathrm{O}_{4}$ after catalysis (Figure 4).

A plausible mechanism for the 2-oxazoline ring formation is depicted in Scheme 2.

\section{Computational Studies}

In the present study, quantum chemical calculations were used initially to optimize the geometry of all the molecules using the density functional theory (DFT), (B3LYP) method, and a $6-311++G(d, p)$ basis set with the aid of Gaussian 09 program package and Gauss View 6.0 [46-49].

The obtained optimized geometries of all the synthesised 2-oxazoline molecules are used as inputs for vibrational frequencies calculations $[51,52]$, and we also computed the variety of properties like bond lengths, bond angles, dihedral angles, dipole moments, molecular electrostatic potential surfaces (MEPS), thermodynamic properties, and global reactivity descriptors at the same level of theory and plotted them using Gauss View 6.0 [53].

The equilibrium geometry optimization of the synthesised 2-oxazoline derivatives has been carried out by energy minimization with the DFT/B3LYP level of theory at the $6-311++G(d, p)$ basis set. The minimum energy of all the compounds is listed in the Table 4.

The optimized geometry, bond lengths, bond orders, and Mullikan charges of compound 3a are shown in Figure 5, and for the remaining compounds, the same has been provided in the supporting information.

As we know, frontier molecular orbitals provide important optical and electric properties as well as the kinetic 
TABLE 1: Optimization of reaction conditions ${ }^{\mathrm{a}}$.



TABLE 2: Substrate scope of the synthesis of various 2-oxazoline derivatives ${ }^{\mathrm{a}}$ under ultrasound and conventional stirring.

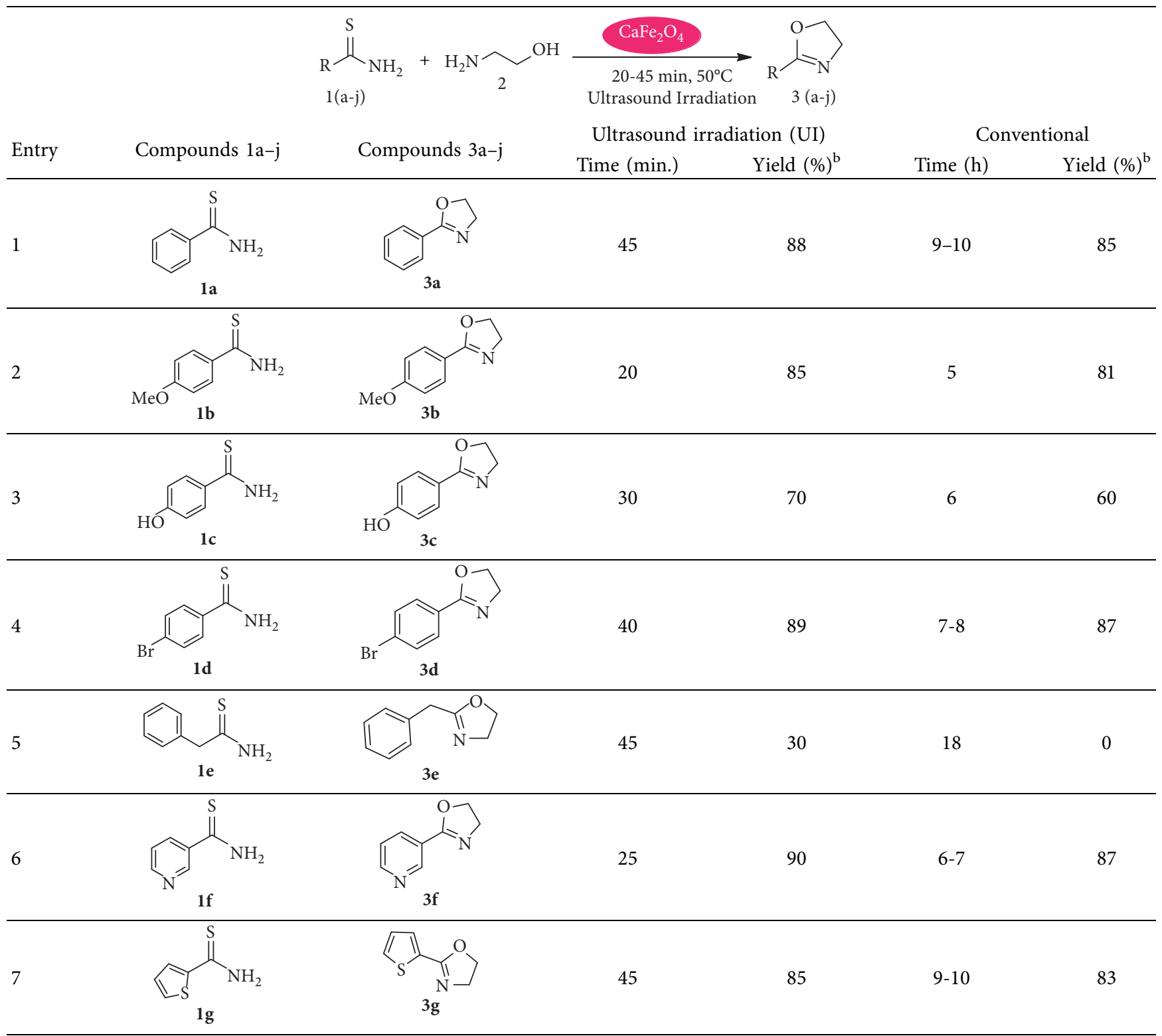


TABLE 2: Continued.

Entry

${ }^{\mathrm{a}}$ Reaction conditions: $\mathbf{1 a}-\mathbf{g}(1 \mathrm{mmol}), 2(1.1 \mathrm{mmol}), \mathrm{CaFe}_{2} \mathrm{O}_{4}(10 \mathrm{~mol} \%), \mathrm{H}_{2} \mathrm{O}, 50^{\circ} \mathrm{C}$, and UI. ${ }^{\mathrm{b}}$ Isolated yield.

TABLE 3: Recycling of $\mathrm{CaFe}_{2} \mathrm{O}_{4}$.

\begin{tabular}{lccc}
\hline Runs & 1 & 2 & 3 \\
\hline Yield (\%) & 85 & 84 & 82 \\
\hline
\end{tabular}

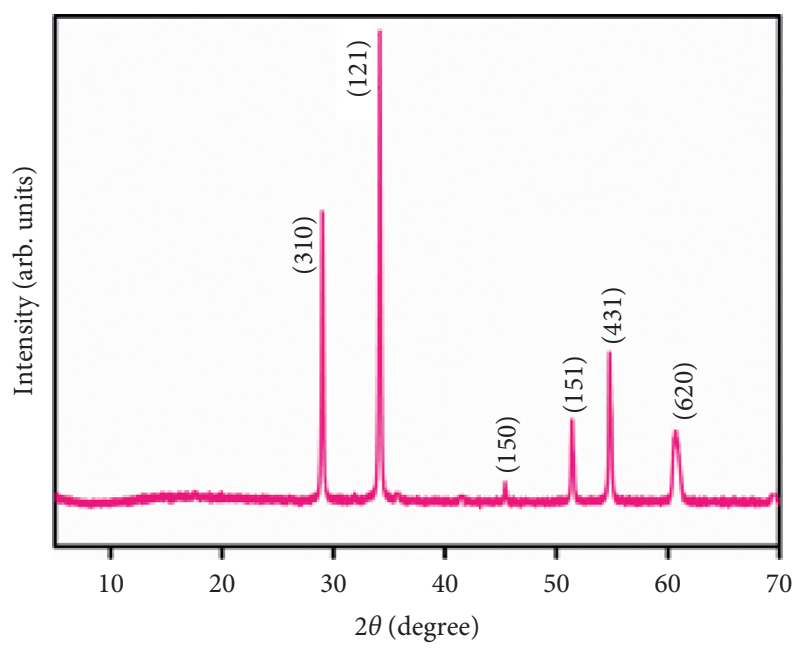

FIGURE 4: XRD pattern of recycled $\mathrm{CaFe}_{2} \mathrm{O}_{4}$ nanoparticles.

stability of chemical molecules [54]. Hence, in the present work, the frontier molecular orbitals are also computed using the DFT/B3LYP method with the $6-311++\mathrm{G}(\mathrm{d}, \mathrm{p})$ basis set. The HOMO and LUMO are useful in determining the molecular reactivity and provide the pathway to interact with other related molecules. Generally, the chemical reactivity and kinetic stability of the molecular systems are characterized by the bandgap (HOMO-LUMO), which plays a very important role in the field of theoretical quantum chemistry. The frontier molecular orbitals are also useful to predict whether the studied molecular system belongs to a chemically soft or hard group [55-57]. The pictorial representation of HOMO and LUMO of compound $\mathbf{3 a}$ is shown in Figure 6, and the calculated energies of HOMO and LUMO are listed in Table 4. The HOMO and LUMO pictorial representations of all other molecules are provided in the supporting information.

\section{Global Reactivity Descriptors}

The global reactivity descriptors of synthesised 2-oxazoline derivatives are calculated within the framework of DFT $[58,59]$. The ionization potential and electron affinity of the molecule are calculated as per the Janak theorem [60] and Perdew et al. [61]. On the basis of Koopman's theorem, global reactivity and site selectivity are also determined for the synthesised molecules $[62,63]$. The formulas for the global reactivity descriptors are listed in Table 5.

All the global reactivity descriptors of 2-oxazoline derivatives are calculated by using the DFT/B3LYP method with the $6-311++G[49,59]$ basis set, and the calculated values are listed in Table 6 .

In the present finding, the molecule $\mathbf{3} \mathbf{j}$ has the highest value of $\eta, \mathbf{3 i}$ has the highest value of $\mu, \mathbf{3} \mathbf{g}$ has the highest value of $S, \mathbf{3 f}$ has the highest value of $\omega$, and $\chi$ and $\Delta N_{\max }$ have the maximum value for the molecule $\mathbf{3 d}$. The $\mathbf{3 d}$ molecule transfers maximum charge in the direction of the electrophile. The parameter $\Delta E_{\mathrm{back}}$ - donation has a maximum value for the molecule $3 \mathrm{~g}$, which provides valuable information about the reactive behavior of the molecular systems via the electronic back-donation process.

\section{Molecular Electrostatic Potential Map}

The behavior and reactivity of the molecules with other chemical species provides data about the shapes of the 


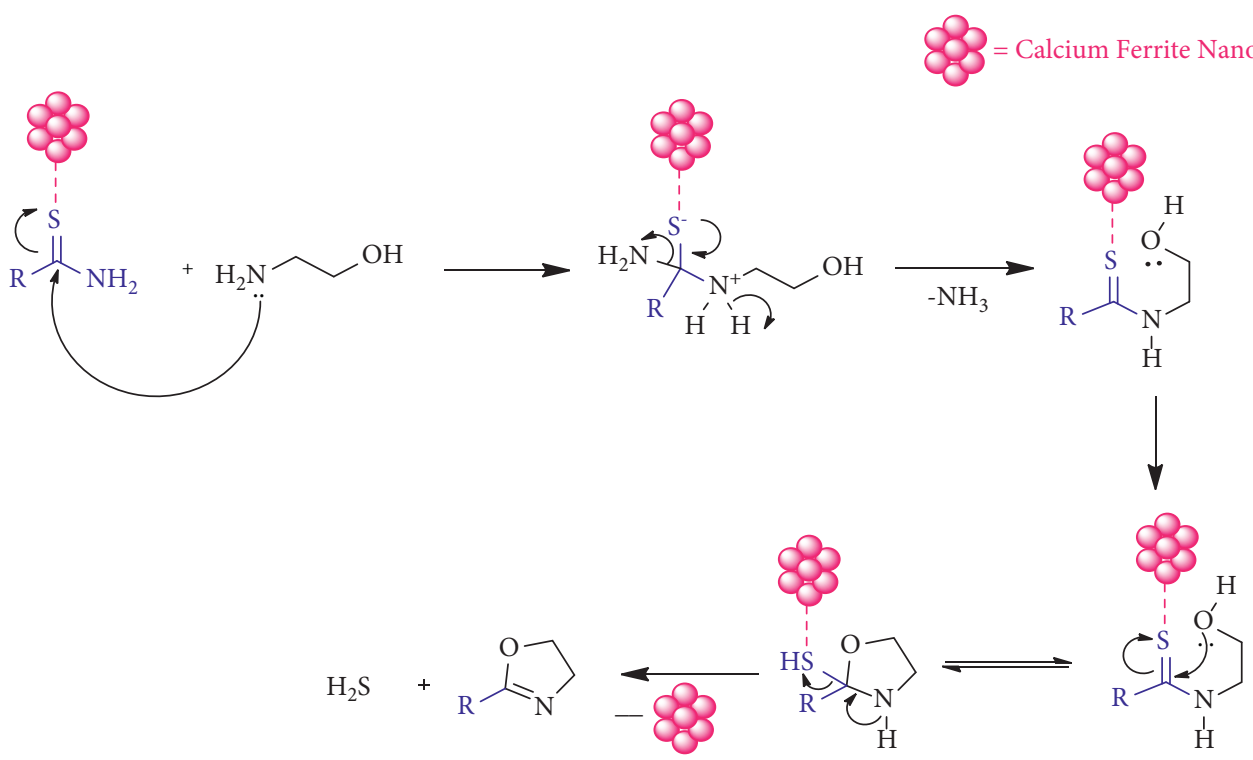

Scheme 2: Plausible mechanism.

TAвle 4: Details of minimum energy, $E_{\mathrm{HOMO}}, E_{\mathrm{LUMO}}$, energy gap, dipole moment, and polarizability $(\alpha)$ of 2-oxazoline derivatives.

\begin{tabular}{|c|c|c|c|c|c|c|}
\hline S. no. & Entry & Structure & Energy (hartree) & $E_{\text {HOMO }}(\mathrm{ev})$ & $E_{\text {LUMO }}(\mathrm{ev})$ & Energy gap (ev) \\
\hline 1 & $3 \mathbf{a}$ & & -478.47 & -0.2437 & -0.0497 & 0.1940 \\
\hline 2 & $3 b$ & & -593.03 & -0.2253 & -0.0390 & 0.1863 \\
\hline 3 & $3 c$ & & -553.72 & -0.2301 & -0.0413 & 0.1889 \\
\hline 4 & $3 d$ & & -3052.01 & -0.2456 & -0.0599 & 0.1857 \\
\hline 5 & $3 e$ & & -517.79 & -0.2530 & -0.0218 & 0.2312 \\
\hline 6 & $3 \mathrm{f}$ & & -494.51 & -0.2537 & -0.0613 & 0.1924 \\
\hline 7 & $3 g$ & & -799.23 & -0.2371 & -0.0562 & 0.1809 \\
\hline 8 & $3 h$ & & -482.10 & -0.2505 & -0.0096 & 0.2409 \\
\hline 9 & $3 \mathbf{i}$ & & -404.66 & -0.2523 & -0.0028 & 0.2495 \\
\hline 10 & $3 \mathbf{j}$ & & -286.69 & -0.2543 & -0.0027 & 0.2516 \\
\hline
\end{tabular}




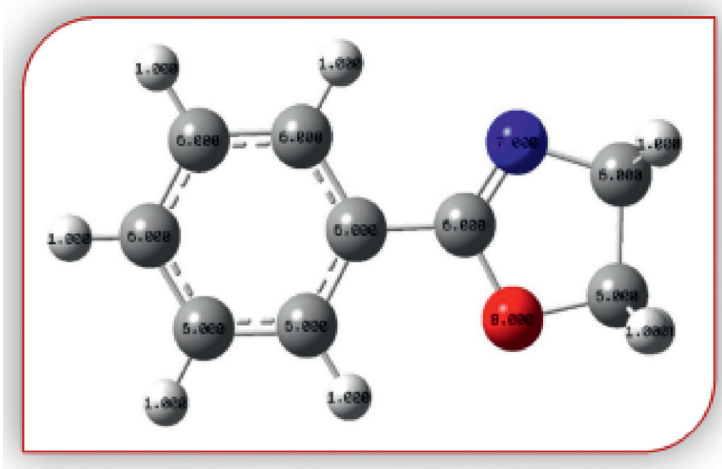

Optimized Molecular Geometry

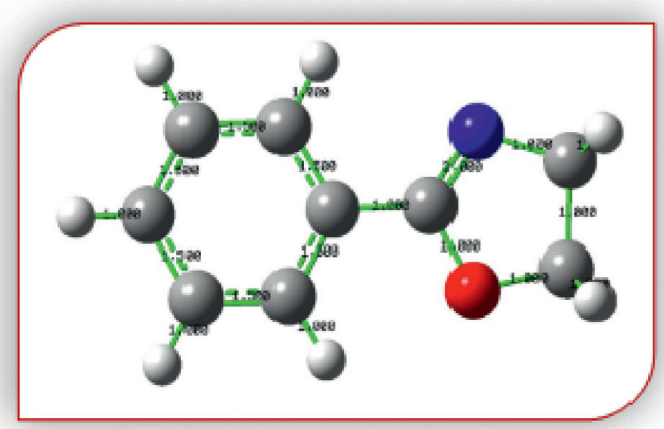

Bond Orders

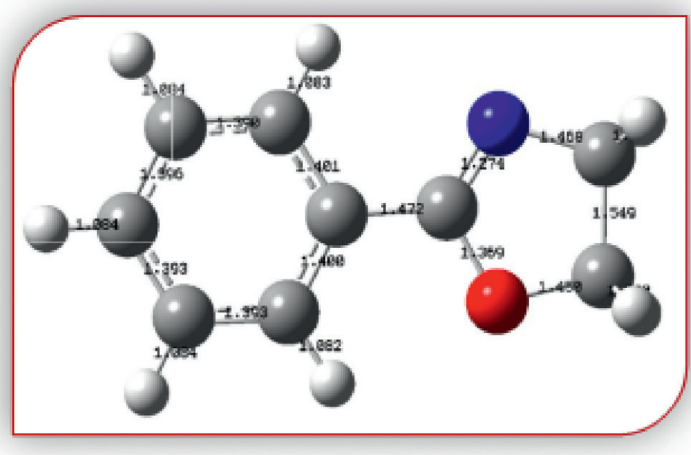

Bond Lengths



Mullikan Charges

Figure 5: 2-Phenyl oxazoline (3a).

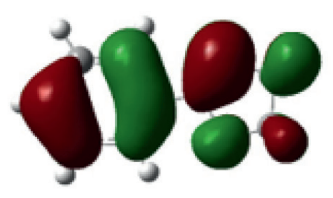

$\mathrm{E}_{\mathrm{LUMO}}=-0.0497$

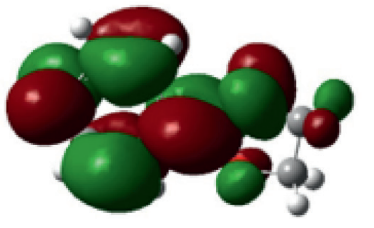

$\mathrm{E}_{\mathrm{HOMO}}=-0.2437$

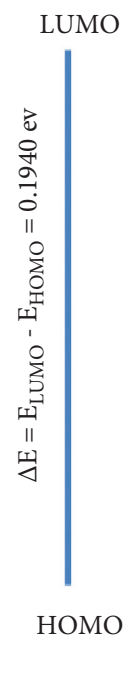

TOMO 
TABLE 5: Formulas for global reactivity descriptors.

\begin{tabular}{lcr}
\hline S. no. & Descriptor & Formula \\
\hline 1 & Ionization potential & IE $=-E_{\mathrm{HOMO}}$ \\
2 & Electro affinity & EA $=-E_{\mathrm{LUMO}}$ \\
3 & Chemical hardness & $\eta=($ IE - EA $) / 2$ \\
4 & Chemical potential & $\mu=-((\mathrm{IE}+\mathrm{EA}) / 2)$ \\
5 & Global softness & $S=(1 / \eta)$ \\
6 & Electro negativity & $\chi=(($ IE + EA $) / 2)$ \\
7 & Electrophilicity index & $\omega=\left(\mu^{2} / 2 \eta\right)$ \\
8 & Maximum charge transfer & $\Delta N_{\text {max }}=-(\mu / \eta)$ \\
9 & Energy change & $\Delta E_{\text {back-donation }}=-(\eta / 4)$ \\
\hline
\end{tabular}

TABLE 6: Calculated values of global reactivity descriptors.

\begin{tabular}{lccccccccc}
\hline Entry & IE & EA & $\eta$ & $\mu$ & $S$ & $\chi$ & $\omega$ & $\Delta N_{\text {max }}$ & $\Delta E_{\text {back }- \text { donation }}$ \\
\hline 3a & 0.2437 & 0.0497 & 0.0970 & -0.1467 & 10.3093 & 0.1467 & 0.1109 & 1.5124 & -0.0243 \\
3b & 0.2253 & 0.0390 & 0.0932 & -0.1322 & 10.7354 & 0.1322 & 0.0937 & 1.4187 & -0.0233 \\
3c & 0.2301 & 0.0413 & 0.0944 & -0.1357 & 10.5904 & 0.1357 & 0.0975 & 1.4369 & -0.0236 \\
3d & 0.2456 & 0.0599 & 0.0929 & -0.1528 & 10.7701 & 0.1528 & 0.1256 & 1.6451 & -0.0232 \\
3e & 0.2530 & 0.0218 & 0.1156 & -0.1374 & 8.6505 & 0.1374 & 0.0817 & 1.1886 & -0.0289 \\
3f & 0.2537 & 0.0613 & 0.0962 & -0.1575 & 10.3950 & 0.1575 & 0.1289 & 1.6372 & -0.0241 \\
3g & 0.2371 & 0.0562 & 0.0905 & -0.1467 & 11.0558 & 0.1467 & 0.1189 & 1.6213 & -0.0226 \\
3h & 0.2505 & 0.0096 & 0.1205 & -0.1301 & 8.3022 & 0.1301 & 0.0702 & 1.0797 & -0.0301 \\
3i & 0.2523 & 0.0028 & 0.1248 & -0.1276 & 8.0160 & 0.1276 & 0.0652 & 1.0224 & -0.0312 \\
3j & 0.2543 & 0.0027 & 0.1258 & -0.1285 & 7.9501 & 0.1285 & 0.0657 & 1.0217 & -0.0314 \\
\hline
\end{tabular}

chemical molecules with positive, negative, and neutral electrostatic potential regions represented by blue, red, and green colors. Generally, MEP maps are obtained by the mapping of electrostatic potential onto the total electron density with color code. The surfaces with blue and red colors represent the positive and negative values of the potentials, while the green color indicates zero potential. $[64,65]$. The MEP map for the synthesised 2-oxazoline derivatives is computed by using the DFT/B3LYP method with the $6-311++G[49,59]$ basis set with level of theory as shown in Figure 7 for the $\mathbf{3 a}$ with a color range from $4.254 E-2$ (deepest red) to $+4.254 E-2$ (deepest blue). The red-colored surfaces with negative MEP corresponds to high electron density, demonstrating the strong attraction between the proton and points on the molecular surface. The blue-colored surfaces with positive MEP correspond to areas of the lowest electron density. The MEP maps of the remaining compounds are provided in the supporting information.

The positive regions of MEP are preferred sites for nucleophilic attacks, while the negative regions are preferred sites for electrophilic attacks. Knowledge about reactive sites in a molecule permits experts to investigate the possible interactions of complex drugs with proteins.

\section{Other Molecular Properties}

DFT can also be used to calculate various thermodynamic properties of molecular systems that can help in understanding chemical processes, including the design of viable industrial chemical processes [66]. The thermodynamic parameters are obtained at $298.15 \mathrm{~K}$ and $1.00 \mathrm{~atm}$ pressure by the vibrational frequency calculations at the DFT/B3LYP/ 6-311G(d, p) level of theory and are depicted in Table 7. The dipole moment and polarizability are also important molecular properties of the various molecular systems for providing information about the charge density, reactivity index, and distribution of charge within a molecule [67-69]. The determined dipole moment, polarizability, and thermodynamic parameters of all the synthesised 2-oxazoline derivatives are also listed in Table 7.

\section{General Procedure}

7.1. Synthesis of Calcium Ferrite Nanoparticles. $0.5 \mathrm{M}$ of $\mathrm{Ca}$ $\left(\mathrm{NO}_{3}\right)_{2} \cdot 4 \mathrm{H}_{2} \mathrm{O}$ and $1.0 \mathrm{M}$ of $\mathrm{Fe}\left(\mathrm{NO}_{3}\right)_{3} .9 \mathrm{H}_{2} \mathrm{O}$ were dissolved separately in distilled water and mixed completely using a magnetic stirrer at $70^{\circ} \mathrm{C}$. Subsequently, $6 \mathrm{M} \mathrm{NaOH}$ solution was added dropwise with the help of a burette until the $\mathrm{pH}$ of the solution reached 12 . Then, the addition of $\mathrm{NaOH}$ was stopped and stirred for some more time. The mixture resulted in the formation of a precipitate. The resulting precipitate was stirred at $70^{\circ} \mathrm{C}$ for $2.5 \mathrm{~h}$. After that, it was filtered and washed with ethanol followed by deionized water until pH 7 was reached and then dried at $60^{\circ} \mathrm{C}$. To get a crystalline product, the resulting powder was calcined at $300^{\circ} \mathrm{C}$ for $2.5 \mathrm{~h}$ in a muffle furnace.

7.2. Synthesis of 2-Oxazolines by the Ultrasonic Irradiation Method. To a mixture of thioamide $\mathbf{1}(\mathbf{a}-\mathbf{j})$ ( $1 \mathrm{mmol})$ and aminoethanol 2 (1.1 mmol), $\mathrm{CaFe}_{2} \mathrm{O}_{4}$ nanoparticles $(10 \mathrm{~mol} \%)$ were added with stirring and the reaction was stirred at $50^{\circ} \mathrm{C}$ under sonication for the time detailed in Table 2 . The progress 

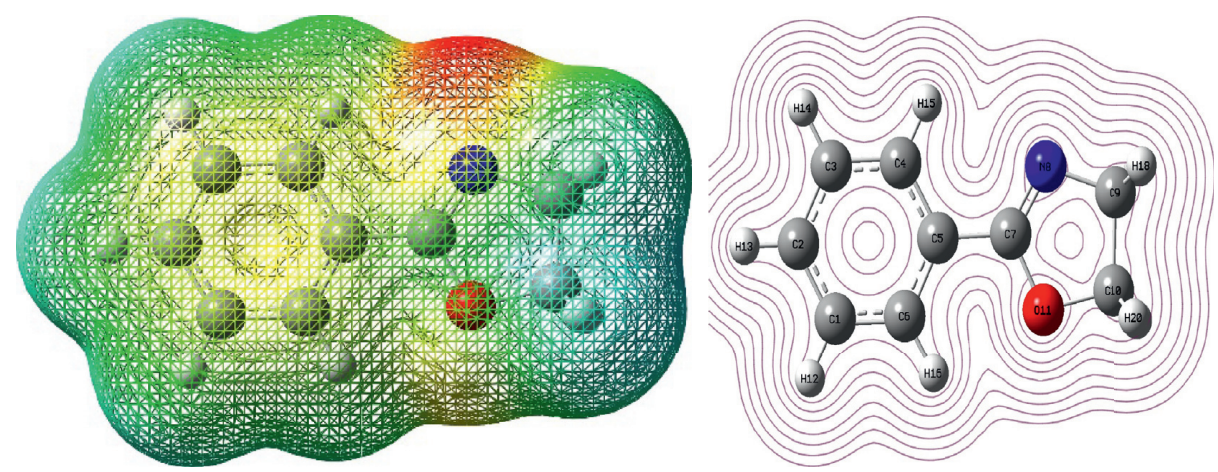

FIGURE 7: Illustration of MEP surface for compound 3a.

TABLe 7: Dipole moment, polarizability, and thermodynamic parameters of 2-oxazoline derivatives.

\begin{tabular}{|c|c|c|c|c|c|}
\hline \multirow{2}{*}{ Entry } & \multicolumn{3}{|c|}{ Thermodynamic parameters } & \multirow{2}{*}{$\begin{array}{c}\text { Dipole moment }(\mu) \\
(\text { debye })\end{array}$} & \multirow{2}{*}{$\begin{array}{c}\text { Polarizability }(\alpha) \\
\text { (a.u.) }\end{array}$} \\
\hline & $E_{\text {Thermal }}(\mathrm{K} \mathrm{cal} / \mathrm{mol})$ & $C_{V}(\mathrm{cal} / \mathrm{mol}-\mathrm{K})$ & $S(\mathrm{cal} / \mathrm{mol}-\mathrm{K})$ & & \\
\hline $3 \mathbf{a}$ & 107.35 & 33.46 & 96.40 & 1.22 & 115.04 \\
\hline $3 b$ & 129.18 & 42.77 & 108.93 & 0.43 & 137.46 \\
\hline $3 c$ & 110.62 & 38.260 & 100.86 & 0.62 & 122.17 \\
\hline $3 d$ & 101.85 & 37.78 & 108.32 & 2.81 & 139.55 \\
\hline $3 e$ & 125.97 & 38.26 & 103.78 & 1.49 & 122.38 \\
\hline $3 f$ & 99.85 & 32.56 & 95.88 & 3.64 & 109.84 \\
\hline $3 g$ & 86.04 & 31.42 & 94.66 & 1.55 & 110.61 \\
\hline $3 h$ & 151.78 & 39.06 & 102.36 & 1.38 & 113.11 \\
\hline $3 \mathbf{i}$ & 121.19 & 34.79 & 100.39 & 1.36 & 93.40 \\
\hline $3 \mathbf{j}$ & 72.14 & 20.29 & 78.00 & 1.37 & 56.27 \\
\hline
\end{tabular}

of the reaction was monitored by TLC. After completion, the reaction mixture was filtered and washed with ethyl acetate 2-3 times. $\mathrm{CaFe}_{2} \mathrm{O}_{4}$ nanoparticles were separated, and the filtrate was concentrated. To remove the excess 2 -aminoethanol in some cases after solvent removal, crude was passed through a short plug of silica gel. Analytical data of all the synthesised compounds can be found in the literature [34].

\section{Analytical Data of Some Representative Compounds}

8.1. 2-Phenyl-4,5-dihydrooxazole (3a) [34]. Colorless oil; yield: $200 \mathrm{mg}(88 \%) .{ }^{1} \mathrm{H} \mathrm{NMR}\left(400 \mathrm{MHz} \mathrm{CDCl}_{3}\right): \delta=4.07(\mathrm{t}$, $\mathrm{J}=9.6 \mathrm{~Hz}, 2 \mathrm{H}), 4.44(\mathrm{t}, \mathrm{J}=9.6 \mathrm{~Hz}, 2 \mathrm{H}), 7.41(\mathrm{t}, \mathrm{J}=8.0 \mathrm{~Hz}, 2$ $\mathrm{H}), 7.46(\mathrm{t}, \mathrm{J}=4.2 \mathrm{~Hz}, 1 \mathrm{H}), 7.94(\mathrm{~d}, \mathrm{~J}=8.4 \mathrm{~Hz}, 2 \mathrm{H})$, (ESIMS): $\mathrm{m} / \mathrm{z}=147[\mathrm{M}+]$.

8.2. 2-(4-Bromophenyl)-4,5-dihydrooxazole (3d) [34]. Light yellow solid; yield: 250 (89\%); mp 94-96 ${ }^{\circ} \mathrm{C} .{ }^{1} \mathrm{H}$ NMR $\left(400 \mathrm{MHz}, \mathrm{CDCl}_{3}\right): \delta=4.05(\mathrm{t}, \mathrm{J}=9.6 \mathrm{~Hz}, 2 \mathrm{H}), 4.44(\mathrm{t}$, $\mathrm{J}=9.6 \mathrm{~Hz}, 2 \mathrm{H}), 7.55(\mathrm{~d}, \mathrm{~J}=8.8 \mathrm{~Hz}, 2 \mathrm{H}), 7.80(\mathrm{~d}, \mathrm{~J}=8.8 \mathrm{~Hz}, 2$ $\mathrm{H}),(\mathrm{ESI}-\mathrm{MS}): \mathrm{m} / \mathrm{z}=225[\mathrm{M}+], 227(\mathrm{M}+2)$.

8.3. 2-(Pyridin-3-yl)-4,5-dihydrooxazole (3f) [34]. Light yellow solid; yield: $150 \mathrm{mg}(88 \%)$; mp $65-67^{\circ} \mathrm{C}$. $1 \mathrm{H}$ NMR $\left(400 \mathrm{MHz}, \mathrm{CD}_{3} \mathrm{OD}\right): \delta=3.87(\mathrm{t}, \mathrm{J}=12.0 \mathrm{~Hz}, 2 \mathrm{H}), 3.94(\mathrm{t}$, $\mathrm{J}=11.6 \mathrm{~Hz}, 2 \mathrm{H}), 7.46(\mathrm{dd}, \mathrm{J}=4.8,4.8 \mathrm{~Hz}, 1 \mathrm{H}), 8.17(\mathrm{td}$,
$\mathrm{J}=2.0,2.0 \mathrm{~Hz}, 1 \mathrm{H}), 8.59(\mathrm{dd}, \mathrm{J}=1.4,1.4 \mathrm{~Hz}, 1 \mathrm{H}), 8.89$ (d, $\mathrm{J}=2.4 \mathrm{~Hz}, 1 \mathrm{H})$. MS (ESI-MS): $\mathrm{m} / \mathrm{z}=148[\mathrm{M}+]$.

\section{Conclusion}

In conclusion, we have succeeded in developing an efficient and operationally simple ultrasound-accelerated strategy for the synthesis of 2-oxazoline derivatives. This has been developed through the use of calcium ferrite nanoparticles. Moreover, the avoidance of workup makes this protocol easy to execute for the synthesis of a wide variety of 2-oxazolines. This methodology follows the green chemistry principle as it is completely devoid of the use of any solvent and adorned with operational simplicity and economic viability in an ecofriendly time- and costeffective manner. The products were obtained in good yields with short reaction times, and the protocol accommodates a variety of functionalities. Furthermore, 2-oxazoline derivatives are used as intermediates in the synthesis of biologically active drug molecules and are also used to prepare efficient catalysts for organic transformations. In order to use the 2-oxazoline derivatives in the abovementioned processes, there is a need to know the properties of these derivatives. In this regard, we have studied the properties of these synthesised derivatives using DFT. Therefore, we can use any one of the derivatives based on the requirements in our future research work.

\section{Data Availability}

Supporting information is provided with the manuscript. 


\section{Conflicts of Interest}

The authors declare that there are no conflicts of interest.

\section{Acknowledgments}

The authors Anjaneyulu Bendi, Nutan Sharma, Shalu, and Mohd. Jamshaiya Raza express gratitude to the Management of SGT University, and G.B. Dharma Rao convey his sincere thanks to the management of KPRIT, Hyderabad, for providing the facilities to conduct the research work and submit this article for publication. The authors also convey their gratitude to Manoj. P. Singh, Advanced Instrumentation Research Facility, Jawaharlal Nehru University, for the $\mathrm{XRD}$ analysis of calcium ferrite nanoparticles.

\section{Supplementary Materials}

DFT study data of all the final compounds are available in the supplementary information file. (Supplementary Materials)

\section{References}

[1] S. Tilvi and K. S. Singh, "Synthesis of oxazole, oxazoline and isoxazoline derived marine natural products: a review," Current Organic Chemistry, vol. 20, Article ID 898, 2016.

[2] F. Plisson, P. Prasad, X. Xiao et al., "Callyspongisines A-D: bromopyrrole alkaloids from an Australian marine sponge, callyspongia sp," Journal of Organic \& Biomolecular Chemistry, vol. 12, Article ID 1579, 2014.

[3] G. C. Moraski, M. Chang, A. Villegas-Estrada, S. G. Franzblau, U. Mollmann, and M. Miller, "Structure-activity relationship of new anti-tuberculosis agents derived from oxazoline and oxazole benzyl esters," European Journal of Medicinal Chemistry, vol. 45, Article ID 1703, 2010.

[4] B. Pfeiffer, K. Hauenstein, P. Merz, J. Gertsch, and K.-H. Altmann, "Synthesis and SAR of C12-C13-oxazoline derivatives of epothilone A," Bioorganic \& Medicinal Chemistry Letters, vol. 19, Article ID 3760, 2009.

[5] L. T. Tan, R. T. Williamson, W. H. Gerwick, K. S. Watts, K. McGough, and R. Jacobs, "cis,cis- and trans,trans-ceratospongamide, new bioactive cyclic heptapeptides from the Indonesian red alga Ceratodictyon spongiosum and symbiotic sponge Sigmadocia symbiotica," Journal of Organic Chemistry, vol. 65, Article ID 419, 2000.

[6] B. S. Davidson, "Ascidians: producers of amino acid-derived metabolites," Chemistry Review, vol. 93, Article ID 1771, 1993.

[7] P. J. Guiry and G. C. Hargaden, "Recent applications of oxazoline-containing ligands in asymmetric catalysis," Chemistry Review, vol. 109, Article ID 2505, 2009.

[8] J. S. Cannon and L. E. Overman, "Palladium(II)-Catalyzed enantioselective reactions using COP catalysts," Accounts of Chemical Research, vol. 49, 2016.

[9] G. Yang and W. Zhang, "Renaissance of pyridine-oxazolines as chiral ligands for asymmetric catalysis," Chemical Society Reviews, vol. 47, Article ID 1783, 2018.

[10] G. Desimoni, G. Faita, and K. A. Jørgensen, "Update 1 of: C2symmetric chiral bis(oxazoline) ligands in asymmetric catalysis," Chemical Reviews, vol. 111, no. 11, pp. PR284-PR437, 2011.

[11] A. I. Meyers and T. G. Gant, "The chemistry of 2-oxazolines (1985-present)," Tetrahedron, vol. 50, pp. 2297-2360, 1994.
[12] O. Sedlacek, D. Bera, and R. Hoogenboom, "Poly(2-amino-2oxazoline)s: a new class of thermoresponsive polymers," Polymer Chemistry, vol. 10, no. 34, pp. 4683-4689, 2019.

[13] J. H. Jeong, S. H. Song, D. W. Lim, H. Lee, and T. G. Park, "DNA transfection using linear poly(ethylenimine) prepared by controlled acid hydrolysis of poly(2-ethyl-2-oxazoline)," Journal of Controlled Release, vol. 73, no. 2-3, pp. 391-399, 2001.

[14] A. I. Meyers and J. Slade, "Asymmetric addition of organometallics to chiral ketooxazolines. preparation of enantiomerically enriched alpha-hydroxy acids," Journal of Organic Chemistry, vol. 45, no. 14, pp. 2785-2791, 1980.

[15] K. Kamata, I. Agata, and A. I. Meyers, "An efficient and versatile method for the synthesis of optically active 2-oxazolines: an acid-catalyzed condensation of ortho esters with amino alcohols," Journal of Organic Chemistry, vol. 63, no. 9, pp. 3113-3116, 1998.

[16] S. Sayama, "A convenient synthesis of oxazolines and imidazolines from aromatic aldehydes with pyridinium hydrobromide perbromide in water," Synlett, vol. 2006, no. 10, Article ID 941597, 1484 pages, 2006.

[17] K. Schwekendiek and F. Glorius, "Efficient oxidative synthesis of 2-oxazolines,” Synthesis, vol. 18, pp. 2996-3002, 2006.

[18] M. Ishihara and H. Togo, "Direct oxidative conversion of aldehydes and alcohols to 2-imidazolines and 2-oxazolines using molecular iodine," Tetrahedron, vol. 63, no. 6, pp. 1474-1480, 2007.

[19] N. Karade, G. Tiwari, and S. Gampawar, "Efficient oxidative conversion of aldehydes to 2-substituted oxazolines and oxazines using (Diacetoxyiodo) benzene," Synlett, vol. 2007, no. 12, Article ID 982571, 1924 pages, 2007.

[20] A. L. Marrero-Terrero and A. Loupy, "Synthesis of 2-oxazolines from carboxylic acids and $\alpha, \alpha, \alpha$-Tris (hydroxymethyl) methylamine under microwaves in solvent-free conditions," Synlett, vol. 1996, no. 3, Article ID 5386, 246 pages, 1996.

[21] A. Cwik, Z. Hell, A. Hegedüs, Z. Finta, and Z. Horváth, “A simple synthesis of 2 -substituted oxazolines and oxazines," Tetrahedron Letters, vol. 43, no. 22, pp. 3985-3987, 2002.

[22] R. Kamakshi and B. S. R. Reddy, "An efficient, eco-friendly, one-pot protocol for the synthesis of 2-oxazolines promoted by ionic liquid/indium chloride," Australian Journal of Chemistry, vol. 59, no. 7, pp. 463-467, 2006.

[23] C. O. Kangani, D. E. Kelley, and B. W. Day, "One pot direct synthesis of oxazolines, benzoxazoles, and oxadiazoles from carboxylic acids using the Deoxo-Fluor reagent," Tetrahedron Letters, vol. 47, no. 37, pp. 6497-6499, 2006.

[24] C. O. Kangani and B. W. Day, "A novel and direct synthesis of 1, 3, 4-oxadiazoles or oxazolines from carboxylic acids using cyanuric chloride/indium," Tetrahedron Letters, vol. 50, no. 38, pp. 5332-5335, 2009.

[25] B. P. Bandgar and S. S. Pandit, "Direct synthesis of 2-oxazolines from carboxylic acids using 2-chloro-4,6-dimethoxy1,3,5-triazine under mild conditions," Tetrahedron Letters, vol. 44, no. 11, pp. 2331-2333, 2003.

[26] V. G. Albano, M. Bandini, M. Monari, E. Marcucci, F. Piccinelli, and A. Umani-Ronchi, "Synthesis and crystallographic characterization of chiral bis-oxazoline-amides. Fine-tunable ligands for Pd-catalyzed asymmetric alkylations," Journal of Organic Chemistry, vol. 71, no. 17, pp. 6451-6458, 2006.

[27] S. Trudeau and J. P. Morken, "StePHOX, a new family of optically active, tunable phosphine-oxazoline ligands: 
syntheses and applications," Tetrahedron, vol. 62, no. 49, pp. 11470-11476, 2006.

[28] B. Ilkgul, D. Gunes, O. Sirkecioglu, and N. Bicak, "Synthesis of 2-oxazolines via boron esters of N-(2-hydroxyethyl) amides," Tetrahedron Letters, vol. 51, no. 40, pp. 5313-5315, 2010.

[29] I. Mohammadpoor-Baltork, A. R. Khosropour, and S. F. Hojati, " $\mathrm{ZrOCl}_{2} \cdot 8 \mathrm{H}_{2} \mathrm{O}$ as an environmentally friendly and recyclable catalyst for the chemoselective synthesis of 2aryloxazolines and bis-oxazolines under thermal conditions and microwave irradiation," Catalysis Communications, vol. 8, no. 2, pp. 200-204, 2007.

[30] I. Mohammadpoor-Baltork, V. Mirkhani, M. Moghadam et al., "Silica sulfuric acid: a versatile and reusable heterogeneous catalyst for the synthesis of oxazolines and imidazolines under various reaction conditions," Catalysis Communications, vol. 9, no. 5, pp. 894-901, 2008.

[31] P. Luo, S. Eriksson, J. Zhou, G. Hu, J. Zhang, and S. Skog, "Thymidine kinase activity in serum of renal cell carcinoma patients is a useful prognostic marker," European Journal of Cancer Prevention, vol. 18, no. 3, pp. 220-224, 2009.

[32] A. Shaabani, M. Seyyedhamzeh, A. Maleki, and F. Rezazadeh, "Cellulose sulfuric acid: an efficient biopolymer-based catalyst for the synthesis of oxazolines, imidazolines and thiazolines under solvent-free conditions," Applied Catalysis A: General, vol. 358, no. 2, pp. 146-149, 2009.

[33] X. Li, B. Zhou, J. Zhang et al., "Solvent-Free tandem synthesis of 2-thiazolines and 2-oxazolines catalyzed by a copper catalyst," European Journal of Organic Chemistry, vol. 2012, no. 8, Article ID 5386, 1632 pages, 2012.

[34] D. R. Goud and U. Pathak, "A mild and efficient synthesis of 2-oxazolines via transamidation-Cyclodehydrosulfurisation of thioamides with 2-aminoethanol," Synthesis, vol. 44, no. 23, pp. 3678-3682, 2012.

[35] H. Marzag, G. Robert, M. Dufies, K. Bougrin, P. Auberger, and R. Benhida, "FeCl3-promoted and ultrasound-assisted synthesis of resveratrol O-derived glycoside analogs," Ultrasonics Sonochemistry, vol. 22, pp. 15-21, 2015.

[36] Y. Q. Liu, L. H. Li, L. Yang, and H. Y. Li, "A novel, stereoselective and practical protocol for the synthesis of $4 \beta$-aminopodophyllotoxins," Chemical Papers, vol. 64, pp. 533-536, 2010.

[37] N. Malik and D. Prasad, "Synthesis and antimicrobial evaluation of N-substituted-5- benzylidene-2,4-thiazolidinedione derivatives," Iranian Journal of Pharmaceutical Sciences, vol. 8, pp. 209-214, 2012.

[38] M. Driowya, A. Puissant, G. Robert, P. Auberger, R. Benhida, and K. Bougrin, "Ultrasound-assisted one-pot synthesis of anti-CML nucleosides featuring 1,2,3-triazole nucleobase under iron-copper catalysis," Ultrasonics Sonochemistry, vol. 19, no. 6, pp. 1132-1138, 2012.

[39] G. Chatel, "How sonochemistry contributes to green chemistry?” Ultrasonics Sonochemistry, vol. 40, pp. 117-122, 2018.

[40] P. Sharma, N. Sharma, G. Kashyap, and S. Bhagat, "A concise and regioselective synthesis of 6-bromo-5-methoxy-1H-indole-3-carboxylic acid and its derivatives: strategic development toward core moiety of Herdmanine D," Synthetic Communications, vol. 50, no. 5, pp. 719-725, 2020.

[41] N. Sharma, P. Kumari, P. Sharma, and S. Bhagat, "Ultrasound-accelerated amide coupling reactions directed toward the synthesis of 1-Acetyl-3-carboxamide- $\beta$-carboline derivatives of biological importance," SynOpen, vol. 1, pp. 8-10, 2017.

[42] V. Polshettiwar, B. Baruwati, and R. S. Varma, "Magnetic nanoparticle-supported glutathione: a conceptually sustainable organocatalyst," Chemical Communications, vol. 14, no. 14, pp. 1837-1839, 2009.

[43] R. B. Nasir Baig and R. S. Varma, "Organic synthesis via magnetic attraction: benign and sustainable protocols using magnetic nanoferrites," Green Chemistry, vol. 15, no. 2, pp. 398-417, 2013.

[44] V. Polshettiwar, B. Baruwati, and R. S. Varma, "Nanoparticlesupported and magnetically recoverable nickel catalyst: a robust and economic hydrogenation and transfer hydrogenation protocol," Green Chemistry, vol. 11, no. 1, pp. 127-131, 2009.

[45] V. Polshettiwar and R. S. Varma, "Nano-organocatalyst: magnetically retrievable ferrite-anchored glutathione for microwave-assisted paal-knorr reaction, aza-michael addition, and pyrazole synthesis," Tetrahedron, vol. 66, no. 5, pp. 1091-1097, 2010.

[46] M. J. Frisch, G. W. Trucks, H. B. Schlegel, G. E. Scuseria, and M. A. Robb, Gaussian 09. Revision A. 1, Gaussian Inc., Wallingford, CT, USA, 2009.

[47] A. D. Becke and J. Chem, "Density-functional thermochemistry III. The role of exact exchange," The Journal of Chemical Physics, vol. 98, no. 7, pp. 5648-5652, 1993.

[48] C. Lee, W. Yang, and R. G. Parr, "Development of the ColleSalvetti correlation-energy formula into a functional of the electron density," Physical Review B, vol. 37, no. 2, pp. 785-789, 1988.

[49] R. Dennington II, T. Keith, and J. Millam, Gauss View, Version 4.1.2, Semichem Inc., Shawnee Mission, KS, USA, 2007.

[50] A. Syed, A. H. Bahkali, and A. M. Elgorban, "Enhanced antibacterial and visible light driven photocatalytic activity of $\mathrm{CaFe}_{2} \mathrm{O}_{4}$ doped $\mathrm{CdO}$ heterojunction nanohybrid particles prepared by sono-chemical method," Optical Materials, vol. 113, Article ID 110595, 2021.

[51] A. P. Scott and L. Radom, "Harmonic vibrational frequencies: an evaluation of Hartree-Fock, Møller-Plesset, quadratic configuration interaction, density functional theory, and semiempirical scale factors," Journal of Physical Chemistry, vol. 100, no. 41, pp. 16502-16513, 1996.

[52] P. Pulay, G. Fogarasi, G. Pongor, J. E. Boggs, and A. Vargha, "Combination of theoretical ab initio and experimental information to obtain reliable harmonic force constants. Scaled quantum mechanical (QM) force fields for glyoxal, acrolein, butadiene, formaldehyde, and ethylene," Journal of the American Chemical Society, vol. 105, no. 24, pp. 7037-7047, 1983.

[53] A. E. Frisch, H. P. Hratchian, R. D. Dennington II et al., Gauss View Version 5.0, Gaussian, Inc, Wallingford, CT, USA, 2009.

[54] B. J. Fleming, Frontier Orbitals and Organic Chemical Reactions, John M'iley u. Sons LTD., London, UK, 1976.

[55] G. Zhang and C. B. Musgrave, "Comparison of DFT methods for molecular orbital eigenvalue calculations," The Journal of Physical Chemistry A, vol. 111, no. 8, pp. 1554-1561, 2007.

[56] M. E. Defonsi Lestard, D. M. Gil, O. Estévez-Hernández, M. F. Erben, and J. Duque, "Structural, vibrational and electronic characterization of 1-benzyl-3-furoyl-1-phenylthiourea: an experimental and theoretical study," New Journal of Chemistry, vol. 39, no. 9, pp. 7459-7471, 2015.

[57] I. Fleming, Frontier Orbitals and Organic Chemical Reactions, Wiley, London, UK, 1976.

[58] R. G. Parr, L. V. Szentpály, and S. Liu, "Electrophilicity index," Journal of the American Chemical Society, vol. 121, no. 9, pp. 1922-1924, 1999. 
[59] P. Chattraj, B. Maiti, and U. Sarkar, "Philicity: a unified treatment of chemical reactivity and selectivity," The Journal of Physical Chemistry A, vol. 107, pp. 4973-4975, 2003.

[60] J. F. Janak, "Proof that $\partial \mathrm{E} / \partial n_{i}=\varepsilon$ in density-functional theory," Physical Review B, vol. 18, no. 12, pp. 7165-7168, 1978.

[61] J. P. Perdew, R. G. Parr, M. Levy, and J. L. Balduz Jr., "Densityfunctional theory for fractional particle number: derivative discontinuities of the energy," Physical Review Letters, vol. 49, no. 23, pp. 1691-1694, 1982.

[62] T. Koopmans, "Über die Zuordnung von Wellenfunktionen und Eigenwerten zu den Einzelnen Elektronen Eines Atoms," Physica, vol. 1, no. 1-6, pp. 104-113, 1934.

[63] B. Gómez, N. V. Likhanova, M. A. Domínguez-Aguilar, R. Martínez-Palou, A. Vela, and J. L. Gázquez, "Quantum chemical study of the inhibitive properties of 2-pyridylazoles," The Journal of Physical Chemistry B, vol. 110, no. 18, pp. 8928-8934, 2006.

[64] F. J. Luque, J. M. López, and M. Orozco, "Perspective on "Electrostatic interactions of a solute with a continuum. A direct utilization of ab initio molecular potentials for the prevision of solvent effects"," Theoretical Chemistry Accounts, vol. 103, pp. 343-345, 2000.

[65] N. Okulik and A. H. Jubert, "Theoretical study on the structure and reactive sites of non-steroidal anti-inflammatory drugs," Journal of Molecular Structure: THEOCHEM, vol. 682 , no. $1-3$, pp. 55-62, 2004.

[66] M. J. Alam and S. Ahmad, "Molecular structure, anharmonic vibrational analysis and electronic spectra of $\mathrm{o}-, \mathrm{m}-$, p-iodonitrobenzene using DFT calculations," Journal of Molecular Structure, vol. 1059, pp. 239-254, 2014.

[67] G. U. Bublitz and S. G. Boxer, "Stark spectroscopy: applications in chemistry, biology, and materials science," Annual Review of Physical Chemistry, vol. 48, no. 1, pp. 213-242, 1997.

[68] J. O. Verbal and L. P. Londono, "Structure-activity relationships for the anti-HIV activity of flavonoids," Journal of Chemical Information and Computer Sciences, vol. 42, pp. 1241-1246, 2002.

[69] T. V. Nguyen and D. W. Pratt, "Hydrogen storage and the 18electron rule," The Journal of Chemical Physics, vol. 124, pp. 1216-1219, 2006. 